Для оценки влияния каждого фактора на выбор технологии строительства быстровозводимых модульных зданий, будет использован метод экспертных оценок, получены показатели по эффективности применения определенной технологии зависимости от территории размещения объектов строительства и выявлена технология, для каждой территории.

$$
* * *
$$

1. Асаул А. Н., Казаков Ю. Н., Князь И. П., Ерофеев П. Ю. Теория и практика использования быстровозводимых зданий в обычных условиях и чрезвычайных ситуациях в России и за рубежом / под ред. Ю. Н. Казакова. СПб.: Гуманистика, 2004. 472 с

2. Исследование факторов совершенствования технологий высокоскоростного модульного строительства / Сычев С.А. - Санкт-Петербург: Вестник ЮУрГУ. Серия «Строительство и архитектура». 2016. Т. 16, № 1. С. $35-40$.

3. S. Russo Ermolli. The environmental benefits of the Off-Site Manufacturing. SB07 Lisbon - Sustainable Construction, Materials and Practices: Challenge of the Industry for the New Millenium, (), 12 Sep 2007 - 14 Sep 2007. Rotterdam (Netherlands)

\title{
Анализ открытого и бестраншейного способа восстановления трубопровода
}

Уральский федеральный университет им. первого Президента России Б.Н.Ельцина (Россия, Екатеринбург)

doi: 10.18411/trnio-11-2021-69

\section{Аннотация}

В статье рассматривается сравнительный анализ способов восстановления трубопровода. Преимущества и недостатки открытого и бестраншейного способа восстановления по ряду критериев оценки. Актуальность внедрения новых технологий при восстановлении наружных сетей.

Ключевые слова: бестраншейный метод, открытый способ, трубопровод, канализация, наружные сети, подземные коммуникации.

\section{Abstract}

The article deals with a comparative analysis of the methods of pipeline restoration. Advantages and disadvantages of open and trenchless recovery method according to a number of evaluation criteria. The relevance of the introduction of new technologies in the restoration of external networks.

Keywords: trenchless method, open method, pipeline, sewerage, external networks, underground communications.

Одной из главных задач коммунальных служб в современных городах является предотвращение старения и преждевременного выхода из строя водопроводных сетей. Особенно это актуально для России, т.к старение подземных трубопроводов и оборудования различного назначения достигают критического значения. Более 50\%подземных коммуникаций уже пережили свой нормативный срок службы. Если не принимать оперативных мер повышения эффективности, работоспособности и реновации подземных трубопроводов, то это усугубит ситуацию многочисленными негативными последствиями для населения и окружающей природной среды.

В настоящее время существует два способа замены канализационных труб: открытым способом и бестраншейным.

Открытый способ: Прокладывание канализации в траншее сопряжено с такими трудностями, как необходимость долгого согласования проекта с инстанциями, чьи интересы будут затронуты при проведении земляных работ. Перекрытие движения по магистралям и пешеходным дорогам, что в результате приведет к нарушению расписания движения 
транспорта, создание дополнительной нагрузки на пути сообщения, рытье траншеи на глубину, регламентируемую ГОСТами, выемка грунта, который после засыпки траншеи оседает, выравнивание дна и укрепление стен траншеи, отсыпка песочной подушки. При сборке линии трубы раскладываются вдоль выкопанной траншеи и подаются краном на место монтажа. Для обеспечения качественного стыка на втулочную поверхность устанавливается резиновая шайба уплотнения. Новая труба вводится в зацепление до полного прижатия, а оставшийся шов подлежит заделке или же осуществляется прокладка полиэтиленовых труб, затем трубы покрывают инертными материалами для защиты от внешних воздействий и засыпают траншеи. Восстановительные работы завершаются благоустройством территорий. Открытый способ замены трубопровода представляет собой трудоёмкий и трудозатратный процесс.

Противоположным способом замены трубопровода является бестраншейная технология.

Бестраншейный способ: Бестраншейная замена труб проводится при условии, когда существующий трубопровод изношен и не может продолжать выполнять свои функции в полной мере. Осуществление работ начинается с осмотра восстанавливаемого участка, гидродинамической или механической промывки трубопровода с его последующей телеинспекцией (видеосъемка роботом). Процесс восстановления представляет собой способ формирования новой трубы внутри существующей трубы коллектора. Формирование новой ПВХ трубы происходит путем прокручивания вокруг своей оси специального профиля ПВХ с замковым соединением. Замковое соединение при этом подвергается процессу холодной сварки, обеспечивая монолитность новой трубы, ее герметичность и прочность. После установки новой ПВХ трубы при необходимости внутри существующей трубы, межтрубное пространство заполняется тампонажным раствором. Заключительным этапом является телеинспекция восстановленного участка трубопровода.

В таблице № 1 представлен сравнительный анализ открытого и бестраншейного способа восстановления трубопровода в зависимости от разных критериев оценки.

Таблица 1

Сравнительный анализ открытого и бестраншейного способа восстановления трубопровода

\begin{tabular}{|c|c|c|c|}
\hline № & $\begin{array}{c}\text { Критерии оценки способов } \\
\text { по замене трубопровода }\end{array}$ & Открытылый способ & Спирально-навивной способ \\
\hline 1 & $\begin{array}{c}\text { Согласование земляных } \\
\text { работ с администрацией }\end{array}$ & $\begin{array}{c}\text { При замене труб открытылм } \\
\text { способом первоначальным } \\
\text { этапом является согласование } \\
\text { земляных работ для разработки } \\
\text { траншеи и демонтажа старой } \\
\text { трубы. Подача документов } \\
\text { осуществляется в местную } \\
\text { Администрацию города через } \\
\text { Госуслуги или лично. Перечень } \\
\text { документов можно посмотреть } \\
\text { на сайте Госуслуг. } \\
\end{array}$ & $\begin{array}{c}\text { В проведение земляных работ } \\
\text { нет необходимости, } \\
\text { восстановление трубы } \\
\text { происходит из уже имеющихся } \\
\text { колодиев путем навивки профиля } \\
\text { ПВХ внутри старой трубы, } \\
\text { улучшая её прочностные } \\
\text { характеристики. }\end{array}$ \\
\hline 2 & $\begin{array}{c}\text { Согласование дорожных } \\
\text { работ (ГИБДД) }\end{array}$ & $\begin{array}{l}\text { В случае если участок находится } \\
\text { в дорожной зоне, необходимо } \\
\text { согласовать производственные } \\
\text { работы с ГИБДД, а именно } \\
\text { перекрытие всей дороги, или же } \\
\text { перекрытие нескольких полос, } \\
\text { что создаст помехи для } \\
\text { передвижения автотранспорта. } \\
\text { Для согласования работ, нужно } \\
\text { предоставить проект } \\
\text { производства работ и схему } \\
\text { организации дорожного } \\
\text { движения, с указанием }\end{array}$ & $\begin{array}{c}\text { Работьы производятся из уже } \\
\text { имеющихся колодчев, } \\
\text { следовательно, при нахождении } \\
\text { колодиев на проезжей части, } \\
\text { необходимо оградить только } \\
\text { небольшую территорию для } \\
\text { установки оборудования. } \\
\text { Согласование дорожных работ } \\
\text { происходит аналогичнымм } \\
\text { образом, но в упрощённой форме. } \\
\text { Нет потребности в перекрытии } \\
\text { дорог, наличие помех } \\
\text { автотранспорту минимально. }\end{array}$ \\
\hline
\end{tabular}




\begin{tabular}{|c|c|c|c|}
\hline & & $\begin{array}{c}\text { ограждений рабочей территории } \\
\text { и установкой дорожных знаков. } \\
\text { При открытом способе } \\
\text { происходит разрушение всего } \\
\text { участка дороги, который } \\
\text { попадает в зону разработки } \\
\text { траншеи. }\end{array}$ & \\
\hline 3 & $\begin{array}{c}\text { Разрушение дорожных } \\
\text { покрытий, благоустроенных } \\
\text { территорий }\end{array}$ & Производится. & Не производится. \\
\hline 4 & $\begin{array}{c}\text { Уничтожение природного } \\
\text { ландшафта, плодородной } \\
\text { почвы }\end{array}$ & $\begin{array}{c}\text { При разработке грунта глубиной } \\
\text { 3-5 метров прочсходит } \\
\text { разрушение плодородной почвы и } \\
\text { нарушение подземной } \\
\text { экосистемьl. }\end{array}$ & Не производится. \\
\hline 5 & $\begin{array}{c}\text { Разработка траншеи на } \\
\text { глубину, регламентируемую } \\
\text { ГОСТами, СП }\end{array}$ & $\begin{array}{c}\text { Разработка осуществляется } \\
\text { согласно нормативным } \\
\text { документам: } \\
\text { СП 45.13330.2017, ГОСТ Р } \\
\text { 12.3.048-2002. }\end{array}$ & Не производится. \\
\hline 6 & $\begin{array}{c}\text { Работа в условиях } \\
\text { стесненной городской } \\
\text { застройки }\end{array}$ & $\begin{array}{c}\text { Разработка грунта согласно } \\
\text { диаетра демонтируемой трубы } \\
\text { с добавлением размеров } \\
\text { безопасной зоны по краям } \\
\text { траншеи, делает возможность } \\
\text { замень трубопровода в } \\
\text { стесненных условиях } \\
\text { затруднительной, либо } \\
\text { невозможной. Затруднения } \\
\text { возникают не только в } \\
\text { передвижении автотранспорта, } \\
\text { но даже в передвижении } \\
\text { пешеходов. }\end{array}$ & $\begin{array}{c}\text { Работы производятся без } \\
\text { затруднений. Помех для } \\
\text { комфортного передвижения } и \\
\text { работ не возникает. }\end{array}$ \\
\hline 7 & $\begin{array}{c}\text { Риск нарушения подземных } \\
\text { коммуникаций, кабельных } \\
\text { линий }\end{array}$ & $\begin{array}{c}\text { Из-за наличия под землей старых } \\
\text { коммуникаций, которые не всегда } \\
\text { можно обнаружить т.к } \\
\text { например, многие чертежи } \\
\text { утеряны с годами, возникает } \\
\text { вероятность повреждения } \\
\text { подземных сетей, что может } \\
\text { привести к аварийным } \\
\text { ситуациям, выходам из строя } \\
\text { какой-либо системы или же } \\
\text { просто нежелательного } \\
\text { разрушения. }\end{array}$ & $\begin{array}{c}\text { Работы осуществляются в уже } \\
\text { имеюшихся, проверенных } \\
\text { участках, землянье работь не } \\
\text { производятся, что делает } \\
\text { работу безопасной. }\end{array}$ \\
\hline 8 & $\begin{array}{c}\text { Демонтаж старого } \\
\text { трубопровода и монтаж } \\
\text { нового }\end{array}$ & Осущеествляется. & $\begin{array}{c}\text { Навивка новой трубы внутри } \\
\text { старой. }\end{array}$ \\
\hline 9 & $\begin{array}{c}\text { Изменение диаметров } \\
\text { восстанавливаемых } \\
\text { трубопроводов }\end{array}$ & $\begin{array}{c}\text { Открытый способ заменьл } \\
\text { трубопровода позволяет } \\
\text { варьировать диаметр новой } \\
\text { трубы в зависимости от } \\
\text { требуемых условий. Ограничений } \\
\text { в размере диаметров нет. }\end{array}$ & $\begin{array}{c}\text { Изменить диаметр невозможно. } \\
\text { Навивка осуществляется внутри } \\
\text { уже имеющейся трубь } \\
\text { заданного диаметра, с } \\
\text { небольшим уменьшением } \\
\text { внутреннего диаметра на 40-120 } \\
\text { мм. }\end{array}$ \\
\hline 10 & $\begin{array}{c}\text { Прекращчение подачи воды, } \\
\text { установка отводов }\end{array}$ & $\begin{array}{c}\text { Для осуществления работ } \\
\text { открытым способом нужно } \\
\text { остановить поток воды или } \\
\text { перенаправить его по } \\
\text { установленным временнымм } \\
\text { отводам, прокладывая их } \\
\text { параллельно. }\end{array}$ & $\begin{array}{c}\text { Восстановление трубопровода } \\
\text { осуществляется без остановки } \\
\text { имеющихся стоков. }\end{array}$ \\
\hline
\end{tabular}




\begin{tabular}{|c|c|c|c|}
\hline 11 & Природные факторы & $\begin{array}{c}\text { Прочесс производства работ } \\
\text { напрямую зависит от погодных } \\
\text { условий. При пониженных } \\
\text { температурах работы } \\
\text { выпполняются крайне редко, } \\
\text { только в аварийных ситуация т.к } \\
\text { разработка грунта затруднена. } \\
\text { Во время осадков открытая } \\
\text { часть участка затапливается и } \\
\text { работы останавливаются. }\end{array}$ & $\begin{array}{c}\text { Работы осуществляется при } \\
\text { любых погодных условиях. Во } \\
\text { время осадков над колодиемем } \\
\text { устанавливают палатку для } \\
\text { комфортного осуществления } \\
\text { работ. Зимой работьы } \\
\text { производятся в палатке, } \\
\text { нагреваемой тепловой пушкой. } \\
\text { Температурный порог от }-25^{\circ} \mathrm{C} \text {. }\end{array}$ \\
\hline 12 & $\begin{array}{c}\text { Контроль производства } \\
\text { работ }\end{array}$ & $\begin{array}{c}\text { Открытый способ замены } \\
\text { трубопровода позволяет } \\
\text { наглядно наблюдать и } \\
\text { контролировать процесс работ, } \\
\text { обеспечивая простоту надзора. }\end{array}$ & $\begin{array}{c}\text { В случае бестраншейного } \\
\text { метода восстановления } \\
\text { трубопровода процесс надзора } \\
\text { усложнен и чаще всего } \\
\text { определяется с помощьью } \\
\text { телеинспекции роботом. }\end{array}$ \\
\hline 13 & Сроки выполнения работ & $\begin{array}{c}\text { Сроки работ варьируются исходя } \\
\text { из протяженности } \\
\text { ремонтируемого участка. При } \\
\text { открытом способе сроки больше } \\
\text { минимум в } 3 \text { раза т.к большую } \\
\text { часть времени занимают } \\
\text { согласования с разными } \\
\text { инстанциями о разрешении } \\
\text { выполнения работ, затем } \\
\text { выполнение строительных } \\
\text { работ: разработка траншей и } \\
\text { демонтаж старой трубы, } \\
\text { установка нового трубопровода и } \\
\text { засыпка траншеи с последующим } \\
\text { благоустройством территории. } \\
\text { Все эти работь требуют } \\
\text { продолжительного количества } \\
\text { затрачиваемых дней, в среднем } \\
\text { до 1-3 месячев. }\end{array}$ & $\begin{array}{c}\text { Расчёт количества рабочих дней } \\
\text { при бестраншейном } \\
\text { восстановлении так же } \\
\text { начинается при необходимости } \\
\text { с согласований, которые обычно } \\
\text { занимают не продолжстельное } \\
\text { время, а затем осуществляется } \\
\text { выполнение производственных } \\
\text { работ, которые включают в } \\
\text { себя промывку имеющегося } \\
\text { трубопровода с последующей } \\
\text { телеинспекией, навивкой } \\
\text { профиля ПвХи забутовкой } \\
\text { межтрубного пространства при } \\
\text { необходимости, и } \\
\text { заключительным этапом } \\
\text { является телеинспекиия после } \\
\text { санации. Сроки работ при } \\
\text { благоприятных стечениях } \\
\text { обстоятельств составляют в } \\
\text { среднем 2-3 недели. }\end{array}$ \\
\hline 14 & Оборудование & Экскаватор, манипулятор & Навивочная машина \\
\hline 15 & Количество рабочих & 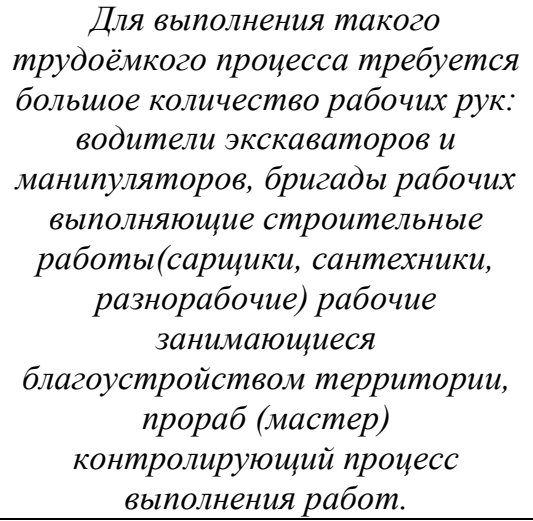 & $\begin{array}{c}\text { Для осуществления работ по } \\
\text { восстановлению трубопровода } \\
\text { требуется бригада рабочих из 3- } \\
5 \text { человек и прораб (мастер) } \\
\text { контролирующий прочесс } \\
\text { выполнения работ. }\end{array}$ \\
\hline 16 & $\begin{array}{l}\text { Благоустройство } \\
\text { территории }\end{array}$ & $\begin{array}{c}\text { Благоустройство территорий } \\
\text { является заключительнымм } \\
\text { этапом выполнения работ и } \\
\text { осуществляется согласно: СП } \\
\text { 82.13330.2016, ГОСТ 32825-2014. } \\
\text { Так же выполняется очистка } \\
\text { территории от строчтельного } \\
\text { мусора. }\end{array}$ & $\begin{array}{c}\text { Не производится т.к в процессе } \\
\text { работ никаких повреждений или } \\
\text { разрушений не осуществляется. } \\
\text { Территория не подвергается } \\
\text { воздействию от } \\
\text { производственного прочесса. }\end{array}$ \\
\hline 17 & $\begin{array}{c}\text { Стоимость выполнения } \\
\text { работ }\end{array}$ & $\begin{array}{c}\text { Прокладьвание трубопровода в } \\
\text { траншее сопряжено с такими } \\
\text { денежными затратами, как }\end{array}$ & $\begin{array}{c}\text { Основные затраты направлены } \\
\text { на строительный материал, } \\
\text { используемый для }\end{array}$ \\
\hline
\end{tabular}




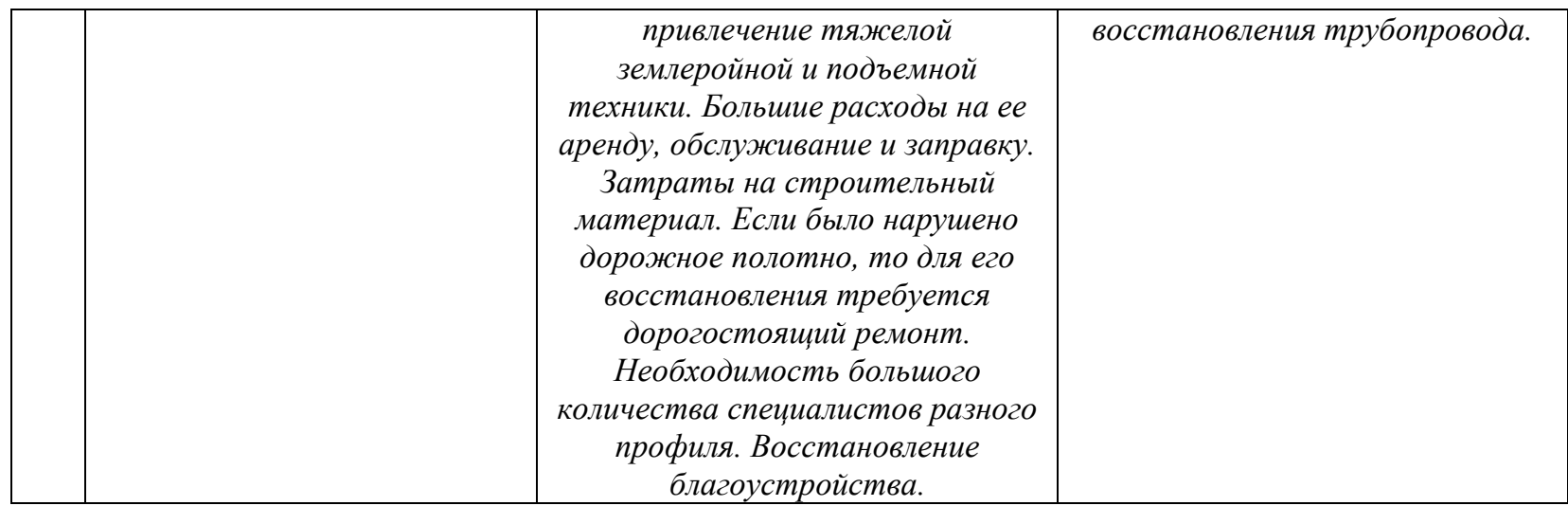

Вывод: При сравнение открытого и бестраншейного метода восстановление трубопровода были выявлены плюсы и минусы каждого метода. На смену старых методов приходят новые и поэтому актуальность применения бестраншейных технологий объясняется неуклонным ростом объемов по освоению подземного пространства, развитием инфраструктуры мегаполисов, ежегодным увеличением объемов по замене трубопроводов подземных инженерных коммуникаций. Появление новых методов решения по восстановление трубопроводов помогут справиться с возникающими затруднениями, а также с сокращением экономических затрат.

$$
* * *
$$

1. Орлов В.А., Орлов Е.В., Зверев П.В. Технологии местного бестраншейного ремонта водоотводящих трубопроводов // Вестник МГСУ. 2013. № 7. С. 86--95.

2. Потапов А.Д., Абрамян С.Г., Ахмедов А.М. Экореконструкция городского пространства Волгограда на принципах субурбанизации городских территорий // Вестник МГСУ. 2014. № 6. С. 105--113. DOI: 10.22227/1997-0935.2014.6.105-113

3. Marlow D., Gould S., Lane B. An expert system for assessing the technical and economic risk of pipe rehabilitation options. Expert Systems with Applications. (2015); Volume: 42 (Iss.22); pp. 8658-8668. DOI: 10.1016/j.eswa.2015.07.020.

\section{Руденя О.М. \\ Основные виды повреждений деревянных конструкций в процессе длительной эксплуатации и методы борьбы с ними}

Санкт-Петербургский государственный архитектурно-строительный университет doi: 10.18411/trnio-11-2021-70

(Россия, Санкт-Петербург)

\section{Аннотация}

В работе проведен анализ характерных дефектов деревянных элементов кровли многоквартирных домов послевоенной постройки города Калининград в процессе длительной эксплуатации. Выявлены закономерности появления и развития повреждений, изучены их влияния на деревянные конструкции, а также отмечены зависимости прочности древесины от вида длительно действовавшего напряженного состояния. Указаны причины, приведшие к возникновению повреждений и рекомендации по устранению и усилению конструкций.

Ключевые слова: элементы стропильной системы, характерные дефекты, влажность древесины, гидроизоляция, пароизоляция, несущая способность, силовые конструкции.

\section{Abstract}

The analysis of the characteristic defects of the wooden elements of the roof of apartment buildings of the post-war construction of the city of Kaliningrad in the process of long-term operation was carried out in the work. The regularities of the appearance and development of damages are revealed, their effects on wooden structures are studied, and the dependences of the 